Joris R. Delanghe and Michael J. Joyner

J Appl Physiol 105:395-396, 2008. First published Jun 26, 2008; doi:10.1152/japplphysiol.90746.2008

You might find this additional information useful...

This article cites 12 articles, 6 of which you can access free at:

http://jap.physiology.org/cgi/content/full/105/2/395\#BIBL

This article has been cited by 2 other HighWire hosted articles:

Comments on Delanghe and Joyner's editorial "testing for recombinant human erythropoietin".

G. Lippi, G. Banfi, J. Morkeberg, B. Belhage, R. Damsgaard and V. Skibeli

J Appl Physiol, December 1, 2008; 105 (6): 1990-1991.

[Full Text] [PDF]

Comments on Lundby et al.'s "testing for recombinant human erythropoietin in urine: problems associated with current anti-doping testing". Problems associated with current anti-doping testing: is quality assessment a reliable solution?

G. Lippi, W. E. Jelkmann, G. L. Salvagno, G. C. Guidi, C. R. Valeri, G. Ragno, B. Kayser, F. Lasne, Y. O. Schumacher, T. Pottgiesser, J. Morkeberg, B. Belhage, R. Damsgaard, V. Skibeli, M. Saugy, N. Robinson, S. Lamon, W. Schanzer and H. Geyer

J Appl Physiol, December 1, 2008; 105 (6): 1992-1993.

[Full Text] [PDF]

Updated information and services including high-resolution figures, can be found at:

http://jap.physiology.org/cgi/content/full/105/2/395

Additional material and information about Journal of Applied Physiology can be found at: http://www.the-aps.org/publications/jappl

This information is current as of March 19, 2009.

Journal of Applied Physiology publishes original papers that deal with diverse areas of research in applied physiology, especially those papers emphasizing adaptive and integrative mechanisms. It is published 12 times a year (monthly) by the American

Physiological Society, 9650 Rockville Pike, Bethesda MD 20814-3991. Copyright (C) 2005 by the American Physiological Society.

ISSN: 8750-7587, ESSN: 1522-1601. Visit our website at http://www.the-aps.org/. 


\title{
Testing for recombinant human erythropoietin
}

\author{
Joris R. Delanghe ${ }^{\mathbf{1}}$ and Michael J. Joyner ${ }^{\mathbf{2}}$ \\ ${ }^{1}$ Department of Clinical Chemistry, Ghent University Hospital, Ghent, Belgium; ${ }^{2}$ Department of Anesthesiology, Mayo Clinic, \\ Rochester, Minnesota
}

ERYTHROPOIETIN (Epo) may have effects on exercise capacity and physiological regulation beyond a simple increase in red cell mass and the associated improvement in oxygen transport (4). In the context of a larger study on this topic, Lundby and colleagues (11) also asked questions about the reliability of urine testing for recombinant human Epo (rHuEpo). They studied eight healthy male subjects during a 4-wk "loading" and 2-wk "boosting" phase of Epo use followed by a 2-wk maintenance phase. In the parent study they showed that the effects of Epo on exercise performance were confined to its impact on red cell mass and not to other physiological effects of the hormone. These results were consistent with ideas about the relationship between maximal oxygen uptake and red cell mass or total body hemoglobin that emerged in the 1950s. The findings are timely and have implications for public policy relating to the control of doping practices. In this short report a number of challenges related to urine testing for Epo are highlighted.

Testing for recombinant Epo in urine may seem practical at first sight but appears to be a very difficult task. The amount of endogenous Epo in urine is extremely low (5). The physiological background for testing Epo in urine is complex and the handling of Epo by the renal tubules is poorly understood (16). Furthermore, exercise-induced renal ischemia and the accompanying postexercise proteinuria may affect the clearance of this $32-$ to $39-\mathrm{kDa}$ protein and the quality of the urine matrix.

The Epo test that has been adopted in World Anti-Doping Agency (WADA)-accredited laboratories is based on isoelectric focusing $(2,10)$. Since the introduction of the test in 2000, Epo-abusing athletes have altered their dosing schemes, proving the initial efficiency of the test. By injecting microdoses of $\mathrm{rHuEpo}$, the window of detection can be reduced to as little as 12-18 h postinjection (8).

Several problems (e.g., the lengthy sample preparation, the low sample load capacity, difficulties with interlaboratory standardization, non-specific binding of the secondary antibody to urinary proteins, sensitivity issues) were already identified in a WADA-commissioned report in 2003 (14). The test requires a 700- to 1,000-fold concentration of the specimen before analysis can be carried out, and the concentrated urine forms a pellet that is difficult to solubilize. Despite this enormous concentration factor, up to $20 \%$ of the investigated samples do not show detectable Epo (14). The non-specific interaction of the used monoclonal antibody with human, bacterial, and yeast proteins is worrisome $(4,6)$. Epo test results are clearly not always interpreted identically (4). The use of the software processing has been criticized (6).

The American WADA-accredited laboratory has performed the direct Epo test on more than 2,600 samples, only nine of

Address for reprint requests and other correspondence: J. R. Delanghe, Univ. Hospital Ghent, De Pintelaan 185, B-9000 Gent, Belgium (e-mail: joris. delanghe@ugent.be). them were found to be positive (3). The low numbers of athletes caught by the test are somewhat contradictory to the overall increase of mean hematocrit values since rHuEpo became available (12). Additionally, in some high profile legal cases in the United States, athletes who were clearly doping with a variety of compounds including Epo "passed" hundreds of individual drug tests.

Along these lines, Lundby et al. (11) convincingly demonstrated that the performance of the urinary Epo test is somewhat disappointing. Although the judgment process of "real" doping cases differs from the one applied in the present study, the high number of false-negative results imply a risk that athletes doping with Epo will avoid detection and damage the fundamental goal of fair competition. The earlier reported flaws of the test help to understand the relatively low efficiency of the direct Epo test and the current results emphasize the need for improving Epo testing.

The detection window for Epo shows an interindividual variation because the actual positivity criteria take into consideration the endogenous Epo production rate, which varies enormously between individuals. In subjects with a naturally elevated or stimulated Epo production rate (altitude training, hypoxic tent, etc.), there is a reduced detection window. The positivity criteria used by anti-doping laboratories are strict and (in the case of the Epo analog darbepoietin) could be adapted by only taking into account the position and the specific distribution of the bands in the most acidic area of the gel and no longer the intensity of the bands. This would rule out the differences in interpretation of the test due to different endogenous Epo levels in individual athletes (8). While the performance of the existing test can likely be improved by paying more attention to the preanalytical care after prelevation of urine specimens (4), there also is concern about proteasetreated urine specimens that could mask Epo abuse (9).

On the other hand, blood-based indirect Epo tests have a better physiological basis and offer the advantage that other kinds of blood doping can also be detected $(1,13,15)$. This approach focuses on consistent tracking and establishes upper limits of normal permitted for competition. The so-called "passport" approach will be further facilitated by the increased availability of well-validated mobile hematological analysis equipment. Longitudinal monitoring of blood profiles and comparing an athlete's individual hematological values against his or her own historical baseline rather than a populationderived threshold further enhances the potency of indirect testing (1). In the Union Cycliste International (UCI), the governing body of cycling, anti-doping program " $100 \%$ Against Doping," an individual hematological profile is created. However, indirect Epo/blood doping detection methods require blood sampling, which is a practical disadvantage. Additionally, various dietary or saline infusion strategies for the purposes of short-term hemodilution are likely being practiced to circumvent the "passport" approach prior to important compe- 
titions (7). Does this mean that a combination of regular tracking tests with random elements along with a marker of whole body fluid status is needed?

In summary, the data provided by Lundby et al. demonstrate that an improvement in the current Epo test is necessary or that a different strategy to detect Epo use and blood doping should be considered. Blood-based indirect Epo tests offer an interesting alternative. The rapidly changing blood doping landscape will definitely encourage the use of indirect Epo/blood doping testing with a much broader application.

\section{REFERENCES}

1. Ashenden M, Varlet-Marie E, Lasne F, Audran M. The effects of microdose recombinant human erythropoietin regimens in athletes. Haematologica 91: 1143-1144, 2006.

2. Catlin D, Nissen-Lie G, Howe C, Pascual JA, Lasne F, Saugy M. Harmonization of the method for the identification of epoetin alfa and beta (rEPO) and darbepoetin alfa (NESP) by IEF-double blotting and chemiluminescent detection. WADA Technical Document TD2007EPO. Accessed June 16, 2008. Available at http://www.wada-ama.org/rtecontent/ document/td2007epo_en.pdf.

3. Catlin D, Green G, Sekera M, Scott P, Starcevic B. False-positive Epo test concerns unfounded. Blood 108: 1778, 2006.

4. Delanghe J, Bollen M, Beullens M. Testing for recombinant erythropoietin. Am J Hematol 83: 237-241, 2008.

5. Emslie KR, Howe C, Trout H. Measurement of urinary erythropoietin levels in athletes. In: Proceedings of the Manfred Donike Workshop, 17th Cologne Workshop on Dope Analysis, Recent Advances in Doping Analysis, Vol. 7, edited Schänzer W, Geyer H, Gotzmann A, Mareck-Engelke U. Cologne: Sport and Buch Strau, 1999, p. 291-299.
6. Franke WW, Heid H. Pitfalls, errors and risks of false-positive results in urinary EPO drug tests. Clin Chim Acta 373: 189-190, 2006.

7. Freund BJ, Montain SJ, Young AJ, Sawka MN, DeLuca JP, Pandolf KB, Valeri CR. Glycerol hyperhydration: hormonal, renal, and vascular fluid responses. J Appl Physiol 79: 2069-2077, 1995.

8. Lamon S, Robinson N, Mangin P, Saugy M. Detection window of Darbepoetin-alpha following one single subcutaneous injection. Clin Chim Acta 379: 145-149, 2007.

9. Lamon S, Robinson N, Sottas PE, Henry H, Kamber M, Mangin P, Saugy M. Possible origins of undetectable EPO in urine samples. Clin Chim Acta 385: 61-66, 2007.

10. Lasne F, de Ceaurriz J. Recombinant erythropoietin in urine. Nature 405: 635, 2000.

11. Lundby C, Achman-Andersen NJ, Thomsen JJ, Norgaard AM, Robach P. Testing for recombinant human erythropoietin in urine: problems associated with current anti-doping testing. J Appl Physiol; doi:10.1152/japplphysiol.90529.2008.

12. Morkeberg J, Saltin B, Belhage B, Damsgaard R. Blood profiles in elite cross-country skiers: a 6-year follow-up. Scand J Med Sci Sports. 2008 Feb 17. [Epub ahead of print].

13. Parisotto R, Wu M, Ashenden MJ, Emslie KR, Gore CJ, Howe C, Kazlauskas R, Sharpe K, Trout GJ, Xie M. Detection of recombinant human erythropoietin abuse in athletes utilizing markers of altered erythropoiesis. Haematologica 86: 128-137, 2001.

14. Peltre G, Thormann W. Evaluation Report of the Urine EPO Test. Paris, France, and Bern, Switzerland: Council of the World Anti-Doping Agency (WADA), 2003.

15. Sharpe K, Ashenden MJ, Schumacher YO. A third generation approach to detect erythropoietin abuse in athletes. Haematologica 91: 356-363, 2006.

16. Skibeli V, Nissen-Lie G, Torjesen P. Sugar profiling proves that human serum erythropoietin differs from recombinant human erythropoietin. Blood 98: 3626-3634, 2001. 